\title{
Dementia care in India: a progress report
}

\section{K. S. Shaji ${ }^{1}$ and Amit Dias ${ }^{2}$}

${ }^{1}$ Assistant Professor of Psychiatry, Government Medical College, Thrissur - 680596, Kerala, India, email drshajiks@sancharnet.in

${ }^{2}$ Epidemiologist and Geriatrician Lecturer, Department of Preventive and Social Medicine, Goa Medical College, Bambolim, Goa - 403202, India

ccording to the $200 \mathrm{I}$ census, India is home to more than 76 million people aged 60 years and over. This age-group, currently only $7.4 \%$ of the population, is expected to grow dramatically in the coming few decades. Analysis of the census data shows substantial variation in the rate of demographic ageing across India: at present, $10.5 \%$ of Kerala's population is older than 60 years, while in Dadra and Nagarhaveli this proportion is only $4 \%$. Regions with more favourable health indicators seem to be ageing faster and the demand for specialist services will soon be evident in such places. There is a growing realisation that the care of older people with disabilities makes enormous demands on their carers. Terms such as 'dementia' and 'Alzheimer's disease' are now better understood. This was not the case when the Alzheimer's and Related Disorders Society of India (ARDSI) initiated awareness programmes. However, dementia remains a largely hidden problem in those disadvantaged parts of India where poverty and illiteracy remain prevalent.

\section{Magnitude of the problem}

Prevalence studies have indicated a lower prevalence of dementia in India than in high-income countries. The reported rates vary widely, from 1.4\% to $4.4 \%$ (Shaji et al, 1996, 2005; Rajkumar \& Kumar, 1996; Rajkumar et al, 1997; Chandra et al, 1998; Vas et al, 200 I). It is estimated that there are already about I.5 million people with dementia in India (compared with 2.9 million in the USA), but this number is likely to increase threefold over the next four decades (Ferri et al, 2005). This estimate is based on the premise that the Indian incidence rates are relatively low and will remain stable over time.

The relatively high prevalence of smoking and the high and rising prevalence of type 2 diabetes are matters of concern in India. These, coupled with anticipated lifestyle changes, could affect the incidence rates and lead to a higher than expected prevalence in the near future. The prevalence of vascular dementia and the importance of vascular risk factors for dementia need to be addressed in future research.

\section{Care of older people}

Public awareness of the mental health problems of old age remains low. People do not differentiate between normal ageing and phenomena that are secondary to conditions such as dementia (Patel \& Prince, 200I) Dementia is not usually identified as a health condition. Even when it is identified, it does not lead to carers receiving practical advice or longer-term support (Shaji et al, 2003).

Most people with dementia are cared for at home, by their families. Most families cannot afford institutional care, which is, in any case, unavailable in most parts of the country. It is still generally considered culturally unacceptable. Most carers are women (10/66 Dementia Research Group, 2004) and caring is associated with economic and psychological strain. Caring can also have an adverse impact on the mental health of the carer (Shaji et al, 2003; 10/66 Dementia Research Group, 2004; Dias et al, 2004). The relative absence of pensions means that older people are financially dependent on their children. Although schemes intended to provide financial assistance for widows and the elderly poor are available in most states, they tend not to be accessed. People with dementia are also eligible for a disability pension under the Disabilities Act, but again there seems to have been very little take-up (10/66 Dementia Research Group, 2004).

In India there is a large network of governmentrun primary health centres and hospitals. These work side by side with extensive private healthcare and notfor-profit providers. Staff shortages and poor infrastructure are common in the government system. Although the services are free, many people choose to seek care under the costly private system (10/66 Dementia Research Group, 2004; Dias et al, 2004). Unfortunately, it is difficult to influence practice, introduce reforms or provide training in the private healthcare sector, given its fragmentary nature. Most private doctors work independently and in relative isolation.

Primary care doctors do not encounter many people with dementia in their practice (Patel \& Prince, 200I). However, people with dementia are increasingly seen at general hospitals, especially those in urban areas. A diagnosis of dementia is often made by physicians, neurologists or psychiatrists. Follow-up care is difficult in the absence of outreach services. Following the announcement, in 1999, of the National Policy for Older People, the government has taken some initiatives in this area. Project NICE (National Initiative on Care for the Elderly) aims to enhance the delivery of care to older people in the community. Two training courses have been established: one a 6 month certificate course in geriatric care and the other
People do not differentiate between normal ageing and phenomena that are secondary to conditions such as dementia.... Dementia is not usually identified as a health condition.

Even when it is identified, it does not lead to carers receiving practical advice or longer-

term support. 
a I-year postgraduate diploma course in integrated geriatric care.

\section{Dementia research}

The networking of Indian dementia researchers began in 1998 at Cochin, with the formation of the 10/66 Dementia Research Group. Seven groups of researchers from six centres in India took part in two pilot studies (Prince et al, 2003; 10/66 Dementia Research Group, 2004). The Indian network developed a community-based intervention programme that takes into consideration the realities of resource-limited settings. A case-finding method was developed that facilitated identification of older people with dementia in the community by health workers after brief training (Shaji et al, 2002). In principle, these health workers could be given more training to provide simple homebased interventions.

The intervention includes provision of information and education about dementia, sustained carer support, and guidance in managing symptoms of dementia. The Goa chapter of the ARDSI recently carried out an innovative intervention trial using a similar strategy (see http://www.dementiagoa.org/research.htm). It recruited local people with no prior experience of dementia care and trained them using locally available resources. This was supported and supervised by local psychiatrists and counsellors. There was provision for both pharmacological and psychosocial interventions. The goal was to meet the health needs of the carer and the person with dementia. Early results from this trial seem promising. More interventions are needed that emphasise the

\section{Many more}

centres offer out-

patient services

for dementia

assessment and

care. These are

usually designated

as 'memory

clinics' or more

specifically as

'dementia clinics'.

These services have

become popular

and are already

much sought after

by families in

regions where they

are operating. use of locally available human resources that are feasible, acceptable and lead to significant improvements in carer mental health, and that are capable of reducing the burden on carers.

\section{Service structures and developments}

The ARDSI, founded in 1993, continues to facilitate service development. Its 14 chapters across India function as a link between families and service providers. Although coverage is minimal, facilities for day care, as well as long-term care facilities, are now available in India. Many more centres offer out-patient services for dementia assessment and care. These are usually designated as 'memory clinics' or more specifically as 'dementia clinics'. These services have become popular and are already much sought after by families in regions where they are operating. Apart from providing valuable local services, these clinics can provide excellent opportunities for training undergraduate and postgraduate medical students.

Geriatrics and geriatric psychiatry are slowly emerging as recognised specialties in India. The government has decided to start geriatric medicine units in all medical colleges in the country, which is a prerequisite for the training of future cadres of general practitioners in the assessment and long-term care of their older patients. Recently, a separate geriatric psychiatry unit was established by the government in the Medical College at Lucknow. All of this indicates the willingness of administrators and policy makers to develop new services for older people. It is important to establish and strengthen centres capable of imparting training in dementia care. These centres can also provide leadership in research and service development.

Dissemination of research findings and the encouragement of research have been identified as important tasks by the Geriatric Psychiatry Specialty section of the Indian Psychiatric Society (Shaji et al, 2004). The Indian Association of Geriatric Mental Health, a newly formed multidisciplinary organisation, shares a similar vision, and is now affiliated to the International Psychogeriatric Association. The efforts of these two organisations, coupled with the advocacy of the ARDSI, can be expected to gather more support in the next few years. This seems likely to create a climate that favours the funding and development of community-based services that better meet the needs of older people with dementia and their families. Researchers have a key role in informing and guiding evidence-based service development in India.

\section{References}

10/66 Dementia Research Group (2004) Care arrangements for people with dementia in developing countries. International Journal of Geriatric Psychiatry, 19, 170-177.

Chandra, V., Ganguli, M., Pandav, R., et al (1998) Prevalence of Alzheimer's disease and other dementias in rural India: the IndoUS study. Neurology, 5I, 1000-1008.

Dias, A., Samuel, R., Patel, V., et al (2004) The impact associated with caring for a person with dementia: a report from the 10/66 Dementia Research Group's Indian network. International Journal of Geriatric Psychiatry, 19, 182-184.

Ferri, C. P., Prince, M., Brayne, C., et al (2005) Global prevalence of dementia: a Delphi consensus study. Lancet, 366, 21 |2-2| 17.

Patel, V. \& Prince, M. (200I) Ageing and mental health in a developing country: who cares? Qualitative studies from Goa, India. Psychological Medicine, 31, 29-38.

Prince, M., Acosta, D., Chiu, H., et al (2003) Dementia diagnosis in developing countries: a cross-cultural validation study. Lancet, 36I, 909-917

Rajkumar, S. \& Kumar, S. (1996) Prevalence of dementia in the community - a rural-urban comparison from Madras, India. Australian Journal of Ageing, 15, 9-13.

Rajkumar, S., Kumar, S. \& Thara, R. (1997) Prevalence of dementia in a rural setting - a report from India. International Journal of Geriatric Psychiatry, 12, 702-707.

Shaji, S., Promodu, K., Abraham,T., et al (1996) An epidemiological study of dementia in a rural community in Kerala, India. British Journal of Psychiatry, I68, 745-749.

Shaji, K. S., Arun Kishore, N. R., Praveen, L., et al (2002) Revealing a hidden problem. An evaluation of a community dementia casefinding program from the Indian 10/66 dementia research network. International Journal of Geriatric Psychiatry, I7, 222-225.

Shaji, K. S., Smitha, K., Praveen Lal, K., et al (2003) Caregivers of people with Alzheimer's disease: a qualitative study from the Indian 10/66 Dementia Research Network. International Journal of Geriatric Psychiatry, 18, I-6

Shaji, K. S., Arun Kishore, N. R., Praveen Lal, K., et al (2004) Better mental health care for older people in India. Indian Journal of Psychiatry, 46, 367-372.

Shaji, S., Bose, S. \& Verghese, A. (2005) Prevalence of dementia in an urban population in Kerala, India. British Journal of Psychiatry, I86, 136-140

Vas, C. J., Pinto, C., Panikker, D., et al (200I) Prevalence of dementia in an urban Indian population. International Psychogeriatrics, 13, 439-450. 